\title{
One-day treatment for lobar pneumonia
}

\author{
D.R. SUT TON, A. C.B. WICKS, and LINDSAY DAVIDSON \\ Department of Medicine, University College of Rhodesia
}

\begin{abstract}
An investigation was undertaken to discover whether a single intramuscular dose of long-acting (or mixed long-acting and crystalline) penicillin or a single day's therapy with oral penicillin was satisfactory treatment for lobar pneumonia. These treatments were compared with standard hospital oral and injection therapies. All the experimental treatment regimes were found to be satisfactory. They provide justification for treating lobar pneumonia on an out-patient basis in order to save hospital admissions.
\end{abstract}

Lobar pneumonia is still a common disease in Africa and accounts for approximately $5 \%$ of the admissions to the medical wards of Harari Central Hospital, Salisbury. Since most patients with lobar pneumonia respond rapidly and satisfactorily to penicillin therapy, we have tried to develop a method of therapy for pneumonia which could be used for treatment on an out-patient basis and so save much needed hospital beds.

Sibellas (1966) reported a series of cases of lobar pneumonia from Ibadan in which $82 \%$ had been treated as out-patients. The therapy she used was a large dose of mixed long-acting and crystalline penicillin on the first day, with further doses on the third and fifth days of the illness. She admitted 18 of her 100 patients because of complications and treated 82 as out-patients. Of these 82, 2 patients died and 10 developed complications requiring admission or additional treatment.

Because of the lack of appreciation of time shown by most of our patients, and because many come from long distances, it is important in selecting out-patient treatment to provide therapy which either can be given as a single dose at the hospital or is sufficiently simple to be completed in one day. This is contrary to current practice (Beaumont, 1966; Co-operative Trial, 1966 ; McDermott, 1967 ; Rusby, 1963), which recommends that antibiotics be continued in the treatment of lobar pneumonia for seven days.

We compared the efficacy of standard hospital oral and injection regimes of treatment with penicillin for four or five days with that of a single dose of a depot penicillin, a single dose of mixed depot and crystalline penicillin, a single dose of a combined penicillin and a single-day oral treatment with a broad-spectrum penicillin. These initial trials were conducted on an in-patient basis.

\section{METHOD}

All patients between the ages of 10 and 50 years with a clinical diagnosis of acute lobar pneumonia presenting untreated at the hospital over the period of the trial were included in the trial with the exception of (1) patients with a past history of cardiorespiratory disease; (2) patients with symptoms of illness for more than seven days; and (3) patients who presented with established complications.

Patients were selected for entry to the trial by one of us, but their allocation to one of the seven treatment schedules was made from a previously arranged randomized list and was unknown to us. The treatment schedules adopted were as follows, A, B, and $C$ being so-called standard regimes, and the remainder (D, E, F, G) being single-dose or single-day treatments :

A crystalline penicillin by intramuscular injection, 1 million units six-hourly for five days;

B crystalline penicillin, 1 million units intramuscularly followed by 500,000 units intramuscularly six-hourly for four days;

C hetacillin, $500 \mathrm{mg}$. immediately and $250 \mathrm{mg}$. six-hourly for five days orally (this is converted to ampicillin in the body);

D a single dose of 1 million units of clemizole penicillin G intramuscularly (Previcillin) (this is an antihistamine penicillin combination which is claimed to have significant blood levels for up to 96 hours);

E a single dose of clemizole penicillin G, 1 million units, plus crystalline penicillin, 1 million units, at the same time by intramuscular injection;

F a dose of $2 \mathrm{ml}$. of Bicillin intramuscularlythis contains 300,000 i.u. crystalline penicillin, 300,000 i.u. procaine penicillin, and 600,000 i.u. benzathine penicillin and is claimed to maintain significant blood levels of penicillin for a week ; 
G a dose of $2 \mathrm{~g}$. of ampicillin together with $1 \mathrm{~g}$. of probenecid followed by an identical dose of ampicillin plus $1 \mathrm{~g}$. of probenecid approximately 12 hours later, both orally.

The only other drugs used were analgesics and sedatives.

The initial diagnosis of lobar pneumonia was made on the clinical history of the illness together with the physical signs of pulmonary consolidation. Chest pain was the most constant feature, being present in all but three patients. All patients had a haemoglobin estimation, differential white cell count and sputum examination performed the morning after admission and radiological confirmation of the diagnosis was obtained in every case.

The clinical course of the illness was assessed by one of us daily. The improvement in well-being and the severity of chest pain experienced by the patients correlated well with the drop in temperature and the radiological and leucocyte count response, but not unexpectedly the physical signs in the chest were variable. Patients whose raised temperature had not fallen to normal levels after five days, and patients in whom a second chest radiograph on the fifth day after treatment showed no improvement, were declared to be failures and different treatment was instituted by the physician responsible for the patient. Six patients, four with tuberculosis and two with chronic non-specific pulmonary fibrosis, who were originally misdiagnosed as lobar pneumonia were withdrawn from the trial and their random number cards were returned to the pack.

\section{RESULTS}

The trial was discontinued after approximately nine months when 150 patients with lobar pneumonia had been admitted to it. This gave approximately 20 patients in each treatment group. One hundred and thirty of these were male and 20 were female. The overall sex-ratio for medical admissions during the time of the trial was 3.2 males to 1 female. Fourteen patients were jaundiced on admission and two patients were judged to have central cyanosis on admission. None of these patients failed to respond to the initial treatment. The distribution of patients within the seven treatment groups was comparable with regard to age (Table I), sex, severity

T A B L E I

AGE DISTRIBUTION OF PATIENTS IN THE TRIAL

\begin{tabular}{c|c|c|c|c|c|c}
\hline \multirow{2}{*}{$\begin{array}{c}\text { Treat- } \\
\text { ment } \\
\text { Group }\end{array}$} & No. & $\begin{array}{c}\text { Mean } \\
\text { Age }\end{array}$ & \multicolumn{4}{|c}{ Age (yrs) } \\
\cline { 4 - 7 } & & $10-19$ & $20-29$ & $30-39$ & $40-50$ \\
\hline A & 20 & 29 & 3 & 7 & 6 & 4 \\
B & 28 & 28 & 6 & 10 & 6 & 6 \\
D & 20 & 31 & 3 & 9 & 4 & 4 \\
E & 19 & 31 & 3 & 5 & 8 & 7 \\
F & 19 & 28 & 6 & 2 & 7 & 4 \\
G & 21 & 31 & 2 & 9 & 4 & 3 \\
\cline { 1 - 6 } Total & 150 & & 26 & 8 & 7 & 4 \\
\hline
\end{tabular}

of disease and site of consolidation (Table II). The right and left lungs were almost equally affected and there were more patients with jaundice and cyanosis in the groups undergoing nonstandard one-day treatment. Gram's stain of sputum on admission showed Gram-positive cocci in 43 of the 80 patients in whom they were sought, but pneumococci were only positively identified in four patients. Numbers of bacilli were seen in the sputum of only one patient, who was later classified as a failure in the trial. Culture of the sputum on the morning after admission showed commensals in $40 \%$ of the cases, but pneumococci were cultured in only 12 out of the first 72 patients $(17 \%)$.

The results of treatment are given in Table III. This shows that the rapidity of the response to treatment was not significantly different in any of the treatment groups and that the number of failures was not significantly different in any group. By the time the temperature had become normal the patients were usually symptom-free

T A B L E I I

\begin{tabular}{|c|c|c|c|c|c|c|c|c|c|c|}
\hline \multirow{2}{*}{$\begin{array}{l}\text { Treat- } \\
\text { ment } \\
\text { Group }\end{array}$} & \multicolumn{2}{|c|}{ Sex } & \multicolumn{2}{|c|}{ No. of Cases with } & \multicolumn{2}{|c|}{ Lobes of Left Lung } & \multicolumn{3}{|c|}{ Lobes of Right Lung } & \multirow{2}{*}{$\begin{array}{c}\text { More } \\
\text { than One } \\
\text { Lobe }\end{array}$} \\
\hline & $\mathbf{M}$ & $\mathbf{F}$ & Jaundice & Cyanosis & Upper & Lower & Upper & Lower & Middle & \\
\hline $\begin{array}{l}\mathbf{A} \\
\mathbf{B} \\
\mathbf{C} \\
\mathbf{D} \\
\mathbf{E} \\
\mathbf{F} \\
\mathbf{G}\end{array}$ & $\begin{array}{l}17 \\
26 \\
13 \\
20 \\
17 \\
17 \\
20\end{array}$ & $\begin{array}{l}3 \\
2 \\
7 \\
3 \\
2 \\
2 \\
1\end{array}$ & $\begin{array}{l}1 \\
1 \\
2 \\
3 \\
3 \\
2 \\
2\end{array}$ & $\begin{array}{l}0 \\
0 \\
0 \\
1 \\
0 \\
0 \\
1\end{array}$ & $\begin{array}{l}2 \\
0 \\
2 \\
0 \\
2 \\
0 \\
1\end{array}$ & $\begin{array}{r}9 \\
10 \\
7 \\
9 \\
6 \\
7 \\
9\end{array}$ & $\begin{array}{l}1 \\
4 \\
0 \\
3 \\
0 \\
4 \\
4\end{array}$ & $\begin{array}{l}3 \\
2 \\
3 \\
5 \\
4 \\
2 \\
1\end{array}$ & $\begin{array}{l}4 \\
2 \\
8 \\
3 \\
6 \\
4 \\
3\end{array}$ & $\begin{array}{r}\mathbf{1} \\
10 \\
0 \\
3 \\
1 \\
2 \\
3\end{array}$ \\
\hline Total & 130 & 20 & 14 & 2 & 7 & 57 & 16 & $\begin{array}{l}20 \\
66\end{array}$ & 30 & 20 \\
\hline
\end{tabular}


T A B L E I I I

RESULTS OF TREATMENT

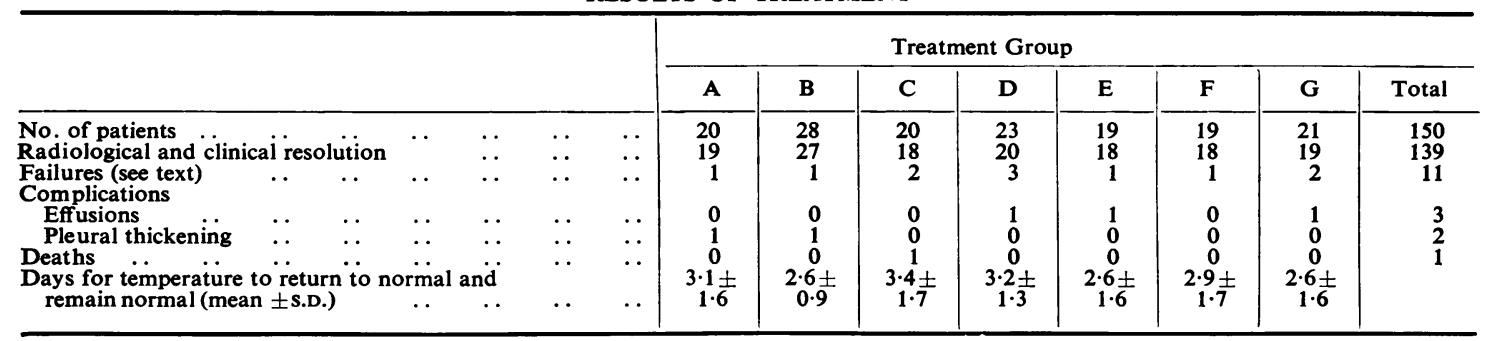

apart from residual sputum production. Three patients developed synpneumonic effusions, but these eventually disappeared without further treatment. Two patients later developed radiological changes on follow-up compatible with residual pleural thickening. Of the 11 patients who failed to respond to the initial treatment, the failure of response did not appear to be related to the presence of jaundice, toxaemia, or the site of consolidation. The average age of these patients was no different from that of the rest of the patients in the trial. Of the failures, the patient in group A who had been treated with crystalline penicillin did in fact respond to treatment-but in seven days rather than five. One patient from each of the other groups was subsequently treated with tetracycline, and in these six patients the satisfactory response coincided with the change in treatment. The two other patients in group $\mathrm{D}$ who had had clemizole penicillin $G$ were changed to intramuscular crystalline penicillin, and their response also coincided with the change in treatment. The second failure in group $G$ who had had ampicillin did not respond to other antibiotics and developed a large pleural effusion with a bronchopleural fistula which later required surgical treatment. The second failure in group $\mathrm{C}$ who died did not respond initially to hetacillin nor subsequently to tetracycline, penicillinaseresistant penicillins or other antibiotics, and was shown at necropsy to have bilateral multiple small staphylococal pulmonary abscesses and staphylococcal pyaemia. ${ }^{1}$

\section{DISCUSSION}

These results show that each of the forms of treatment adopted is effective treatment in the approximately $90 \%$ of patients with uncomplicated lobar pneumonia. Treatments A, B and C could be called standard therapy and were all satisfactory. Treatments $\mathrm{D}, \mathrm{E}$ and $\mathrm{F}$, which all consisted of a single injection of a long-acting penicillin or a mixture of long-acting and crystalline penicillin, were all similarly equally satisfactory. So also was G, the combination of a shortacting oral penicillin plus probenecid given twice at intervals of 12 hours.

It seems clear that any of the experimental forms of treatment could be used as definitive treatment for lobar pneumonia in out-patients provided that the patients have a suitable domestic situation. It is clear also that if the patients have not substantially recovered by the end of five days they should be advised to return to hospital for admission and review of treatment. ${ }^{1}$

The main danger of this approach is misdiagnosis at a clinical level. This happened in the six patients withdrawn from the trial and in one patient admitted to it-a total of 7 in $156(4.5 \%)$. In four of these the misdiagnoses were immediately corrected on examination of the chest radiograph, which suggested that the patients were suffering from pulmonary tuberculosis (which was subsequently proved). In two patients who were suffering from non-specific pulmonary fibrosis the picture was equivocal, and only in the one patient in group $\mathrm{C}$ who died from staphylococcal septicaemia (because penicillin was inappropriate therapy) would out-patient treatment have been dangerous.

Examination of the sputum was not very helpful as a direct Gram stain showed cocci in just over half the patients and recognizable pneumococci in only four patients, and the patient who died from staphylococcal pneumonia had Grampositive cocci in the initial sputum smear. To our surprise, patients with cyanosis, jaundice and with what may be called toxaemia responded just as well to therapy as other patients. We think that

1Nine out of the 11 patients declared fai'ures were finally diagnesed as lobar pneumonia, and were probably only the slowest responses to the initial treatment: three of them were further treated with penicillin, and the remainder with tetracycline. All responded within the next two days after change of treatment, without complications. 
the only patients who require admission to hospital are those suspected of having complications on presentation, or those in whom the combined clinical and radiological features leave room for doubt as to the correct diagnosis.

There appears to be no advantage in using a broad-spectrum penicillin in case the pulmonary infection is due to organisms other than the pneumococcus, for, although this may be necessary in Britain and in other developed countries (Co-operative Trial, 1966), the only patient who died was in fact suffering from staphylococcal pneumonia which did not in any case respond to a broad-spectrum penicillin. The average duration of hospital stay of these patients was one week, and out-patient therapy would, of course, make available for other patients the beds which would otherwise have been occupied by these patients. Of the 156 patients originally admitted to the trial, the 6 patients mis-diagnosed and the 11 failures would have required admission. So the saving in beds would be $89 \%$.

The cost of treatment is also important. Without taking into account hospital services and $x$-ray facilities, the cost of treatment B (crystalline penicillin)-16 injections plus syringes-in Rhodesia is 14 s. (1.95\$U.S.). Treatment G (ampicillin plus probenecid), similarly costed was much more expensive at $29 \mathrm{~s}$. $4 \mathrm{~d}$. (4-10\$U.S.). Treatment
D (1 million units of clemizole penicillin, including disposable syringe and needle but without any allowance for hospital services) cost $5 \mathrm{~s}$. $2 \mathrm{~d}$. in Rhodesia (0.75\$U.S.). Similarly costed treatment $E$ came out at 5 s. 6 d. (0.80\$U.S.) and treatment $F$ at 2 s. $11 \mathrm{~d}$. (0.40\$U.S.).

We conclude, therefore, that out-patient therapy of lobar pneumonia diagnosed clinically and confirmed by a routine chest radiograph is possible, justifiable and inexpensive and we propose to proceed to a practical test of the efficacy of this treatment using clemizole penicillin and Bicillin.

We are grateful to Bristol Laboratories for the provision of the clemizole penicillin G (Previcillin Grunenthal) and hetacillin (ampicillin), to Merck Sharpe \& Dohme, for the provision of the probenicid (Benemid), and to our colleagues in the hospital for allowing us access to their patients.

\section{REFERENCES}

Beaumont, G. E. (1966). In Price's Textbook of Medicine. Ed. Bodley Scott, R., 10th ed., p. 806. Oxford University Press, London. Co-operative Trial (1966). Ampicillin in the treatment of pneumonia . Brit. med. J., 1, 1329 .

McDermott, W. (1967). Cecil-Loeb Textbook of Medicine, 12th ed., p. 144. Ed. Beeson, P. B., and McDermott, W. Saunders, Philadelphia.

Rusby, N. L. (1963). In Chest Diseases, Vol. 2, p. 28, Ed., Perry , K. M. A., and Sellors, T. H. Butterworths, London.

Sibellas, M. (1966). Treatment of lobar pneumonia in out-patients. J. trop. med. Hyg., 69, 94. 